\title{
Mitochondrial dysfunction-associated OPA1 cleavage contributes to muscle degeneration: preventative effect of hydroxytyrosol acetate
}

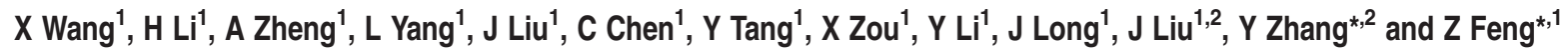

Mitochondrial dysfunction contributes to the development of muscle disorders, including muscle wasting, muscle atrophy and degeneration. Despite the knowledge that oxidative stress closely interacts with mitochondrial dysfunction, the detailed mechanisms remain obscure. In this study, tert-butylhydroperoxide ( $t$-BHP) was used to induce oxidative stress on differentiated C2C12 myotubes. $t$-BHP induced significant mitochondrial dysfunction in a time-dependent manner, accompanied by decreased myosin heavy chain (MyHC) expression at both the mRNA and protein levels. Consistently, endogenous reactive oxygen species (ROS) overproduction triggered by carbonyl cyanide 4-(trifluoromethoxy) phenylhydrazone (FCCP), a mitochondrial oxidative phosphorylation inhibitor, was accompanied by decreased membrane potential and decreased MyHC protein content. However, the free radical scavenger $\mathrm{N}$-acetyl-L-cysteine (NAC) efficiently reduced the ROS level and restored MyHC content, suggesting a close association between ROS and MyHC expression. Meanwhile, we found that both $t$-BHP and FCCP promoted the cleavage of optic atrophy 1 (OPA1) from the long form into short form during the early stages. In addition, the ATPase family gene 3like 2, a mitochondrial inner membrane protease, was also markedly increased. Moreover, OPA1 knockdown in myotubes was accompanied by decreased MyHC content, whereas NAC failed to prevent FCCP-induced MyHC decrease with OPA1 knockdown, suggesting that ROS might affect MyHC content by modulating OPA1 cleavage. In addition, hydroxytyrosol acetate (HT-AC), an important compound in virgin olive oil, could significantly prevent $t$-BHP-induced mitochondrial membrane potential and cell viability loss in myotubes. Specifically, HT-AC inhibited $t$-BHP-induced OPA1 cleavage and mitochondrial morphology changes, accompanied by improvement on mitochondrial oxygen consumption capacity, ATP productive potential and activities of mitochondrial complex I, II and V. Moreover, both $t$-BHP- and FCCP-induced MyHC decrease was sufficiently inhibited by HT-AC. Taken together, our data provide evidence indicating that mitochondrial dysfunction-associated OPA1 cleavage may contribute to muscle degeneration, and olive oil compounds could be effective nutrients for preventing the development of muscle disorders. Cell Death and Disease (2014) 5, e1521; doi:10.1038/cddis.2014.473; published online 13 November 2014

Skeletal muscle is the largest amino acid pool and endocrine organ in the body, and its dysfunction reduces exercise capacity and overall health. ${ }^{1}$ The balance of protein synthesis and degradation sustains regular turnover, but immobilization, ${ }^{2}$ age $^{3}$ cancer cachexia $^{4,5}$ and strenuous exercise ${ }^{6}$ disrupt the balance and contribute to skeletal muscle disorders. Mitochondria work as energy stations and signal transducers to preserve normal organism function, and increasing evidence shows that mitochondrial dysfunction contributes to skeletal muscle disorders. ${ }^{7-9}$ Our previous study showed that strenuous exercise-induced muscle fatigue was accompanied by increased mitochondrial fission, ${ }^{6}$ and an increase in the mitochondrial fission marker dynamin-related protein (DRP1) was found in the skeletal muscle after a high-fat diet was consumed, accompanied by mitochondrial dysfunction and triglyceride accumulation. ${ }^{10}$ These studies indicate that disruption of mitochondrial dynamics plays a vital role during mitochondrial dysfunction-associated muscle disorders.

Optic atrophy 1 (OPA1) is localized on the inner mitochondrial membrane, faces the intermembrane space ${ }^{11}$ and controls mitochondrial inner membrane fusion and remodeling. ${ }^{12}$ Studies have indicated the presence of eight transcript variants, ${ }^{13}$ and OPA1 is differentially proteolyzed into two long and three short isoforms. ${ }^{14,15}$ Different isoforms attach differently to the mitochondrial inner membrane to accurately remodel it and keep the dynamic balance. Previous studies have found that a decreased mitochondrial adenosine 5-triphosphate (ATP) level, generated by either apoptosis induction, mitochondrial membrane potential loss or inhibition of ATP synthase, is the common and crucial stimulus that

\footnotetext{
${ }^{1}$ Center for Mitochondrial Biology and Medicine, The Key Laboratory of Biomedical Information Engineering of the Ministry of Education, School of Life Science and Technology and Frontier Institute of Science and Technology, Xi'an Jiaotong University, Xi'an, China and ${ }^{2}$ Tianjin Key Laboratory of Exercise Physiology \& Sports Medicine, Tianjin University of Sport, Tianjin 300381, China

*Corresponding author: Y Zhang, Tianjin Key Laboratory of Exercise Physiology \& Sports Medicine, Tianjin University of Sport, 51 Weijin South Road, Hexi District, Tianjin 300381, China. Tel: +86 22 23010186; Fax: +86 22 23010186; E-mail: yzhang@tjus.edu.cn

or Z Feng, Center for Mitochondrial Biology and Medicine, School of Life Science and Technology and Frontier Institute of Life Science, Xi'an Jiaotong University, 28 W, Xian-ning Road, Xi'an 710049, China. Tel: +86 29 82665849; Fax: +86 29 82665849; E-mail: zhfeng @ mail.xjtu.edu.cn

Abbreviations: Afg312, ATPase family gene 3-like 2; FCCP, carbonyl cyanide 4-(trifluoromethoxy) phenylhydrazone; HT-AC, hydroxytyrosol acetate; MyHC, myosin heavy chain; Myod, myogenic differentiation 1; NAC, N-acetyl-L-cysteine; OPA1, optic atrophy 1; $t$-BHP, tert-butylhydroperoxide

Received 21.5.14; revised 27.8.14; accepted 06.10.14; Edited by A Finazzi-Agrò
} 
controls OPA1 processing. ${ }^{16,17}$ It is known that the L-forms of OPA1 undergo further processing in the matrix to produce the S-forms and that knockdown of OPA1-induced mitochondrial fragmentation is rescued by expression of the L-forms instead of the S-form of OPA $1 .{ }^{15}$ In addition, the preservation of a stable pool of L-OPA1 at the inner mitochondrial membrane is reported to be sufficient to delay mitophagy and maintain significant mitochondria content. ${ }^{18}$ Regarding OPA1 cleavage, a series of proteases localized to mitochondria including the ATPase family gene 3-like 2 (Afg3l2) and high temperature requirement protein $\mathrm{A} 2(\mathrm{Htr} \mathrm{A} 2)$ are reported to participate in and modulate mitochondria morphology and functional activity. ${ }^{19-21}$ Although several studies have indicated that OPA1-modulated mitochondrial fusion is vital to maintaining mitochondrial and muscle function in various ways, ${ }^{22,23}$ studies on the OPA1 cleavage regulation of oxidative stress and muscle cell disorders remain limited.

Olive oil is an integral ingredient of the 'Mediterranean diet', and accumulating evidence suggests that it may have several benefits with respect to cancer, ${ }^{24}$ metabolic syndrome, ${ }^{25}$ heart function $^{26}$ and muscle function. ${ }^{27}$ The abundant phenolic compounds with antioxidant properties are suggested to make major contributions. Hydroxytyrosol (HT) and hydroxytyrosol acetate (HT-AC) are well-known polyphenolic compounds found in olive oil, and HT-AC showed better antioxidant activity than $\mathrm{HT}^{28}$ In our previous study, we found that HT could prevent strenuous exercise-induced muscle dysfunction, ${ }^{6}$ as well as reduce muscle lipid accumulation in mice fed a high-fat diet. ${ }^{10}$ Since then, no studies have reported the effects of HT$A C$ on muscle disorders. In the current study, we investigated the involvement of OPA1 cleavage and the protective effect of HT-AC on oxidative stress-induced mitochondrial dysfunction and muscle degeneration in $\mathrm{C} 2 \mathrm{C} 12$ myoblast cells.

\section{Results}

Oxidative stress induces rapid mitochondrial dysfunction in muscle cells. To investigate the effects of oxidative stress on mitochondrial function in muscle cells, $100 \mu \mathrm{M}$ tert-butylhydroperoxide $(t-\mathrm{BHP})$ was chosen to challenge differentiated $\mathrm{C} 2 \mathrm{C} 12$ myotubes as an exogenous oxidative stress, following a previous work. ${ }^{6}$ The efficiency of myotube differentiation was verified by immunofluorescence and protein content analysis of myosin heavy chain (MyHC), a major marker of muscle cell, at different time points (Figures $1 \mathrm{a}$ and $\mathrm{b})$. Myotubes were treated with $t$-BHP for the indicated time points $(0,2,6,12$ and $24 \mathrm{~h})$, and mitochondrial membrane potential (MMP), cell viability and cellular ATP content decreased in a time-dependent manner (Figures 1c-e). Similar decrease on cell viability and MMP was also observed in $\mathrm{C} 2 \mathrm{C} 12$ myoblasts without differentiation (Supplementary Figure S1). After $2 \mathrm{~h}$ of treatment, $t$-BHP induced a marked increase in cellular reactive oxygen species (ROS) that generally declined afterwards (Figure 1e).

Oxidative stress includes $\mathrm{C} 2 \mathrm{C} 12$ myotubes degeneration. As shown in Figure 2a, t-BHP induced significant morphology changes in myotubes that became shorter and irregular after $24 \mathrm{~h}$ of treatment. Meanwhile, the protein content of MyHC was found to decrease in a time-dependent manner in $\mathrm{C} 2 \mathrm{C} 12$ myotubes (Figure 2b). In addition, the mRNA expression levels of the MyHC isoforms, MyHC I, Ilb and IIx, were also significantly decreased after $6 \mathrm{~h}$ of $t$-BHP treatment and were reduced by nearly $95 \%$ after $24 \mathrm{~h}$ (Figure $2 \mathrm{c}$ ). As known transcriptional regulators of MyHC, mRNA levels of myogenic differentiation 1 (Myod), Myogenin and Mrf4 were also found decreased dose-dependently by $t$-BHP (Figure 2d). Similar decrease was also observed on Murf-1 and Atrogin-1, the key a

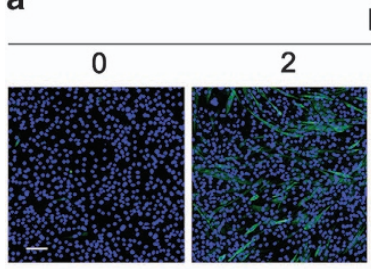

c

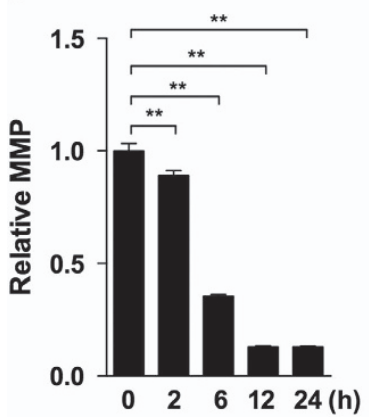

\section{Differentiation}

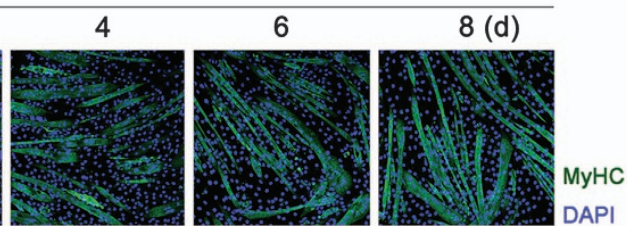

d

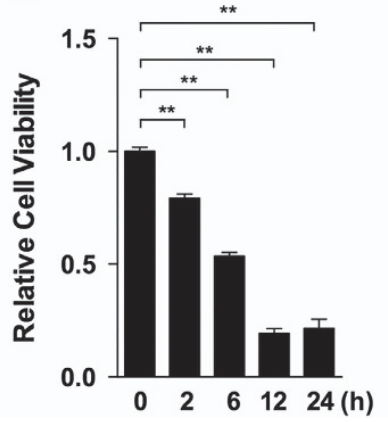

e b
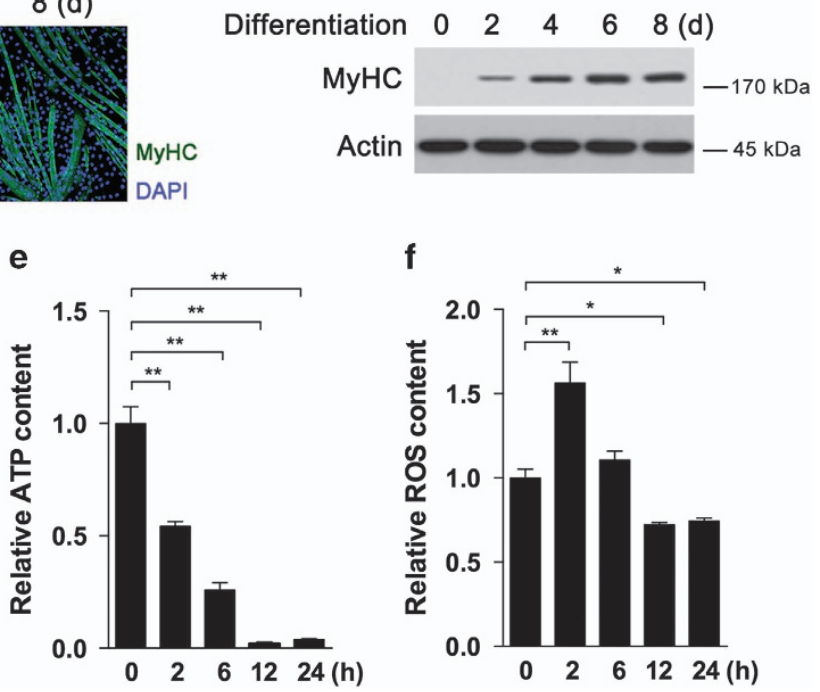

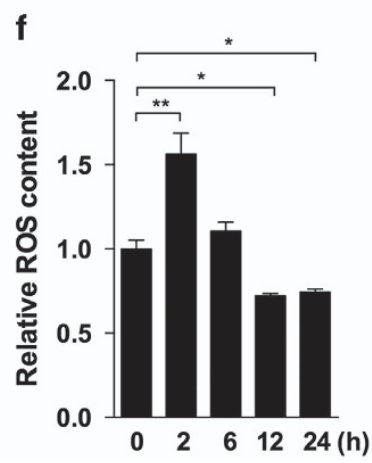

Figure 1 Oxidative stress induces rapid mitochondrial dysfunction in $\mathrm{C} 2 \mathrm{C} 12$ muscle cells. $\mathrm{C} 2 \mathrm{C} 12$ myoblasts were induced into myotubes after 8 days, and immunofluorescence (a) and western blot analysis (b) of MyHC were used to confirm the efficiency of differentiation. After 8 days of differentiation, myotubes were treated with $100 \mu \mathrm{M} \mathrm{t}$-BHP for the indicated time periods, and mitochondrial membrane potential (c), cell viability (d), cellular ATP content (e) and ROS levels (f) were detected. The values are means \pm S.E.M. from at least three independent experiments. ${ }^{*} P<0.05,{ }^{* *} P<0.01$ 
a

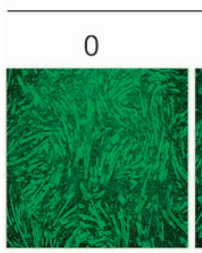

$100 \mu \mathrm{M} t$-BHP
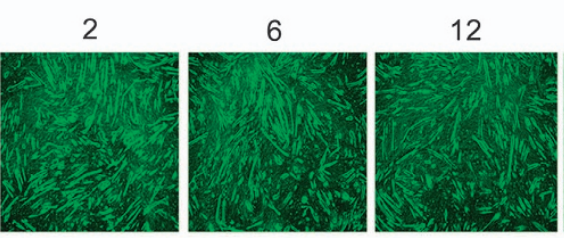

c

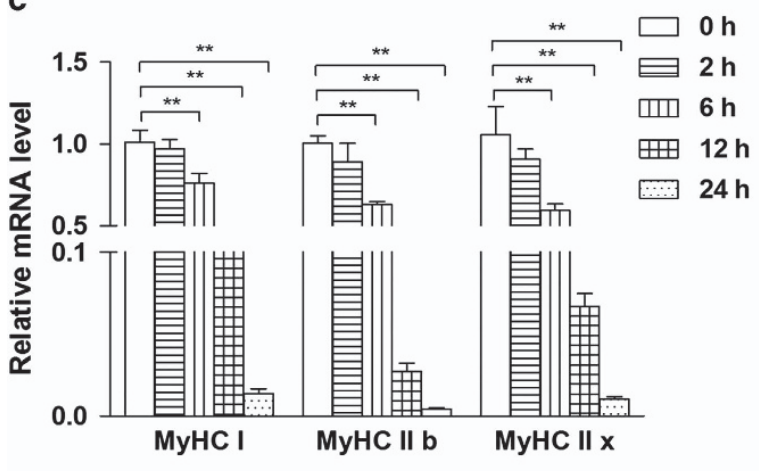

e

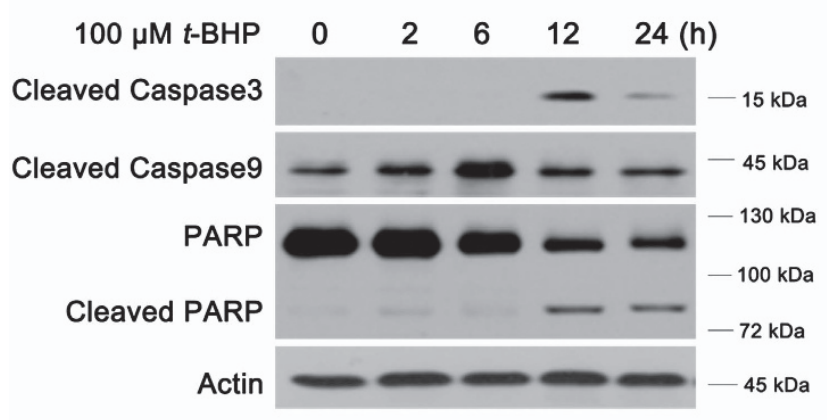

b

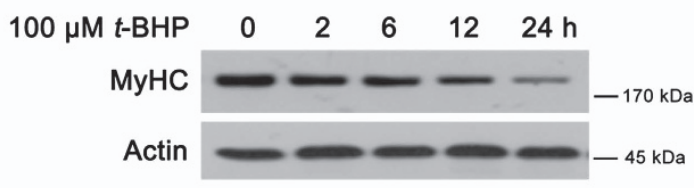

$24 \mathrm{~h}$

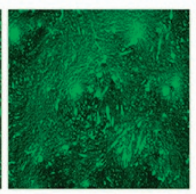

d

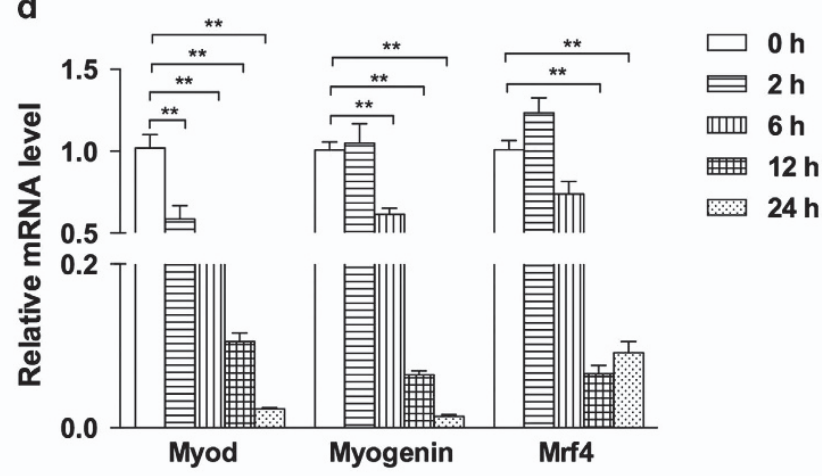

f

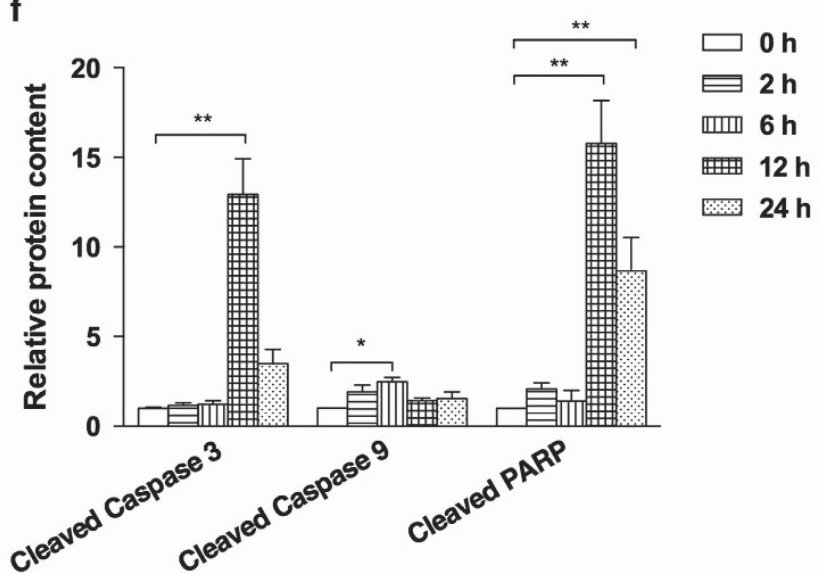

Figure 2 Oxidative stress induces muscle cell degeneration. After 8 days of $\mathrm{C} 2 \mathrm{C} 12$ myoblast differentiation, myotubes were treated with $100 \mu \mathrm{M} t$-BHP for the indicated time points. Cell morphology and myotube structure were observed by microscopy (a). MyHC protein was analyzed by western blotting (b). The mRNA contents of the MyHC isoforms $\mathrm{MyHC} \mathrm{I,} \mathrm{MyHC} \mathrm{Ilb} \mathrm{and} \mathrm{MyHC} \mathrm{IIx} \mathrm{(c)} \mathrm{and} \mathrm{MyHC} \mathrm{regulators} \mathrm{Myod,} \mathrm{Myogenin} \mathrm{and} \mathrm{Mrf4} \mathrm{(d)} \mathrm{were} \mathrm{analyzed} \mathrm{by} \mathrm{real-time} \mathrm{PCR.} \mathrm{Cell} \mathrm{apoptosis} \mathrm{activation} \mathrm{was} \mathrm{confirmed} \mathrm{by} \mathrm{analyzing}$ cleaved caspase 3, cleaved caspase 9, PARP and cleaved PARP ( (e) western blot image; (f) statistical analysis). The values are means \pm S.E.M. from at least three independent experiments. ${ }^{*} P<0.05,{ }^{\star *} P<0.01$

regulators of $\mathrm{MyHC}$ degradation and well-known markers of muscle atrophy (Supplementary Figure S2). Therefore, we proposed that $t$-BHP decreased MyHC content through transcriptional suppression. And, as expected, $t$-BHP induced cell apoptosis activation evidence by increased cleaved caspase 3, cleaved caspase 9 and cleaved PARP (Figures $2 \mathrm{e}$ and $\mathrm{f}$ ).

Mitochondrial ROS overproduction decreases MyHC expression. To further investigate the relationship between mitochondrial dysfunction and myotube degeneration, carbonyl cyanide 4-(trifluoromethoxy) phenylhydrazone (FCCP), a mitochondrial uncoupler, was used to suppress mitochondrial function. FCCP at $20 \mu \mathrm{M}$ induced rapid ROS overproduction at 5 and 15 min (Figures $3 a$ and b) and generally decreased after $2 \mathrm{~h}$ (data not shown). MMP was markedly decreased after FCCP treatment for $2 \mathrm{~h}$, whereas cell viability was not affected (Figure $3 c$ ). Unlike $t$-BHP treatment, FCCP could sharply decrease MyHC protein content after $2 \mathrm{~h}$ (Figures $3 \mathrm{~d}$ and e), and similar protein level was maintained from 6 to $24 \mathrm{~h} . \mathrm{N}$-acetyl-L-cysteine (NAC), the free radical scavenger, was used to eliminate excess ROS induced by FCCP (Figure 3f). As expected, the decrease in MyHC was sufficiently inhibited by NAC (Figures $3 g$ and $h$ ).

Activation of OPA1 cleavage is an early response to oxidative stress. Previous studies have indicated that decreased mitochondrial ATP or mitochondrial membrane potential loss is the common and crucial stimulus that controls OPA1 processing. Here, we found that $t$-BHP promoted rapid OPA1 cleavage from the long form of OPA1 (L-OPA1) into the short form of OPA1 (S-OPA1), accumulated 


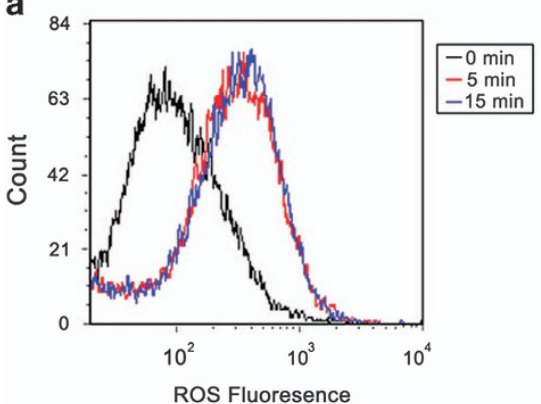

b

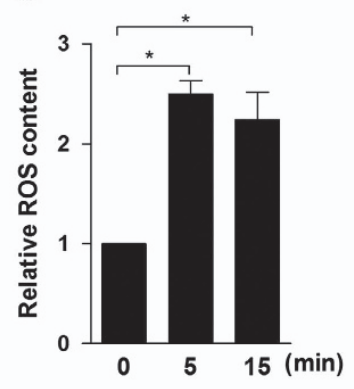

C

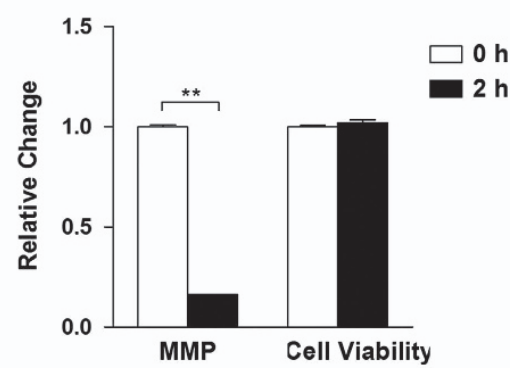

d

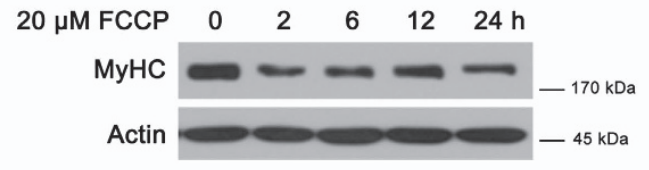

e

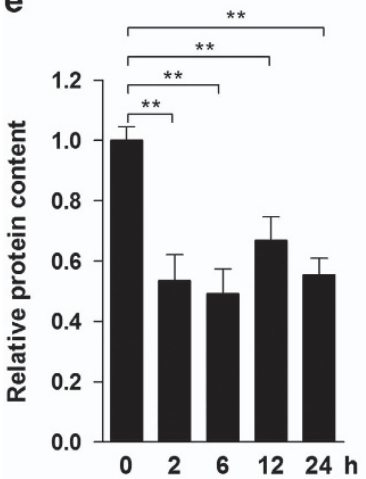

f

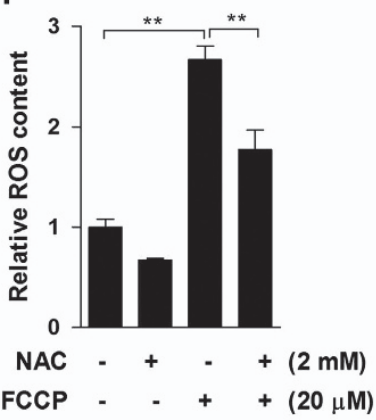

g

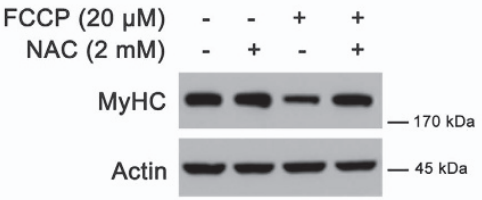

h

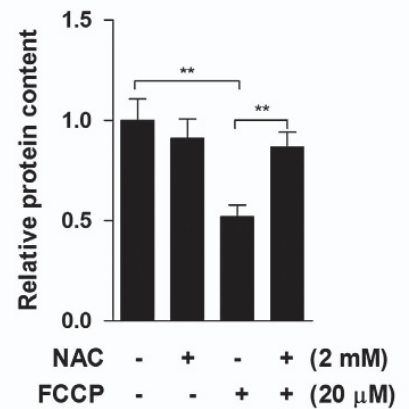

Figure 3 Mitochondrial dysfunction-induced ROS overproduction triggers MyHC decline. After 8 days of differentiation, $\mathrm{C} 2 \mathrm{C} 12$ myotubes were treated with $20 \mu \mathrm{M} \mathrm{FCCP} \mathrm{for} 5$ and $15 \mathrm{~min}$, and the cellular ROS contents were analyzed by flow cytometry ((a) fluorescence curve; (b) statistical analysis). After $2 \mathrm{~h}$ of FCCP treatment, mitochondria membrane potential and cell viability was tested (c). At multiple time points after FCCP treatment, MyHC protein content was analyzed by western blot ((d) western blot image; (e) statistical analysis). Following pretreatment with $2 \mathrm{mM} \mathrm{NAC}$ for $30 \mathrm{~min}, \mathrm{C} 2 \mathrm{C} 12$ myotubes were treated with $20 \mu \mathrm{M} \mathrm{FCCP}$ for 5 min to evaluate the ROS level (f), and for $2 \mathrm{~h}$ to test MyHC protein content by western blot $\left((\mathbf{g})\right.$ western blot image; (h) statistical analysis). Values are means \pm S.E.M. from at least three independent experiments. ${ }^{*} P<0.05,{ }^{* \star} P<0.01$

after $2 \mathrm{~h}$ of treatment (Figures $4 \mathrm{a}$ and $\mathrm{b}$ ). Consistently, FCCP treatment showed a similar pattern of OPA1 cleavage (Figures $4 \mathrm{~d}$ and $\mathrm{e}$ ). The mitochondrial inner protease Afg3l2, which participate in OPA1 cleavage, was found increased time-dependently after both $t$-BHP and FCCP treatment on mRNA levels (Figure 4e) and protein expression (Figures $4 f-h)$.

Oxidative stress decreases MyHC content through activation of OPA1 cleavage. To further investigate the effect of OPA1 on MyHC expression, specific OPA1 siRNA was used to knock down OPA1 expression, and MyHC protein level was found to be decreased significantly (Figures $5 a$ and $b$ ). Because NAC was found to prevent FCCPinduced MyHC decline (Figure $3 \mathrm{~g}$ ), we were able to determine that NAC could significantly inhibit FCCPinduced OPA1 cleavage (Figures $5 \mathrm{c}$ and d). Meanwhile, the preventive effects of NAC on FCCP-induced MyHC decline were abolished by OPA1 siRNA (Figures $5 \mathrm{e}$ and f). The above data suggested that oxidative stress decreased MyHC content through activation of OPA1 cleavage.
Protective effects of HT and HT-AC on $t$-BHP-induced cell toxicity. In our previous study, we found that HT showed protective effects on strenuous exercise-induced muscle damage. ${ }^{6}$ Here we further investigated the potential protective effect and underlying mechanism of HT-AC in an oxidative stress-induced $\mathrm{C} 2 \mathrm{C} 12$ cell toxicity model. As expected, pretreatment with HT-AC for $24 \mathrm{~h}$ showed significant protection at doses of both 10 and $50 \mu \mathrm{M}$ (Figures $6 \mathrm{a}$ and b), indicating that HT-AC might also be an effective nutrient. Further investigation on mitochondrial oxygen consumption and electron transport chain complex activities was conducted with $\mathrm{HT}-\mathrm{AC}$ at the dose of $50 \mu \mathrm{M}$. As shown in Figure 6c, $t$-BHP abolished mitochondrial respiration capacity including basal, maximal, ATP potential and spare respiration, all of which were significantly improved by HT-AC pretreatment (Figures $6 c$ and d). Although mitochondrial content, evidenced by mitochondrial complex subunit expression, was not affected by either $t$-BHP or HT-AC (Figure 6e), the activities of mitochondrial complex I, II and V were decreased by $t$-BHP and then restored to normal levels by HT-AC pretreatment (Figure 6f). 
a

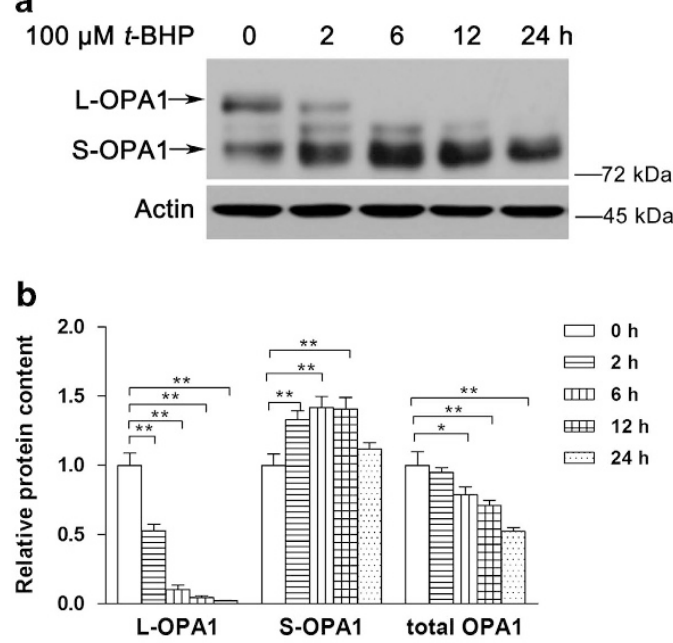

c

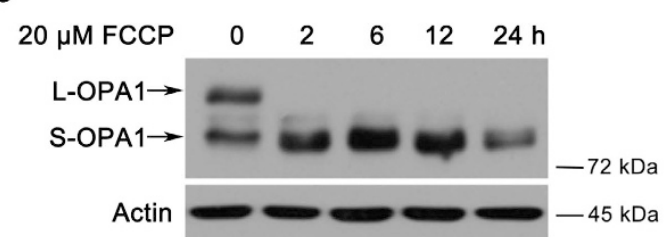

d

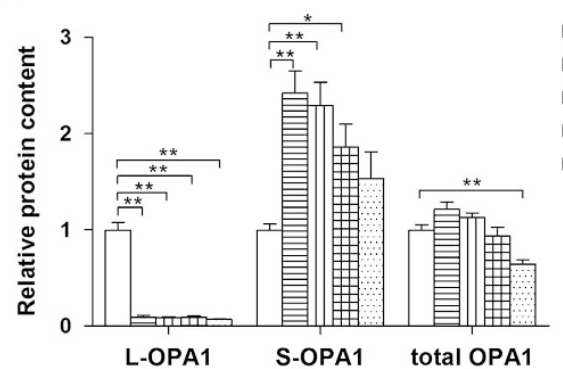

e

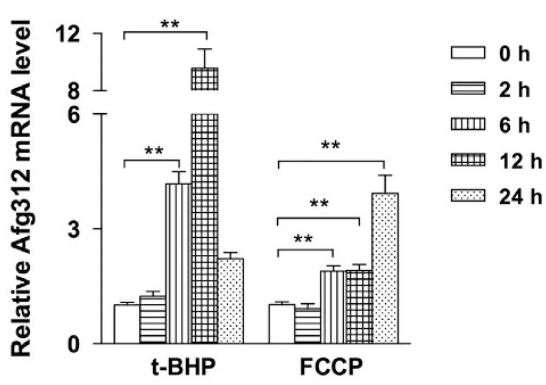

f $100 \mu \mathrm{M} t$-BHP $\quad 0 \quad 2 \quad 6 \quad 12 \quad 24(\mathrm{~h})$

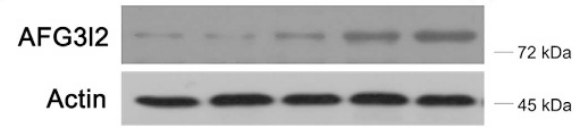

g

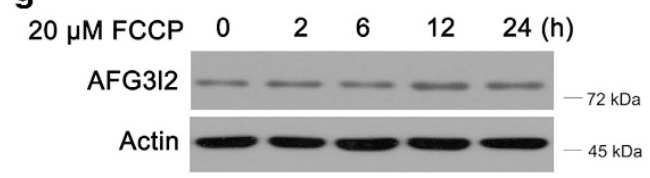

h

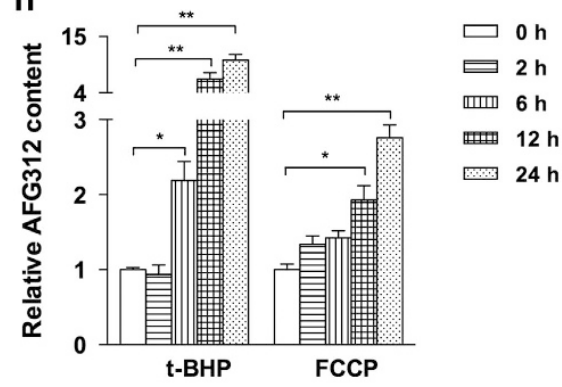

Figure 4 Activation of OPA1 cleavage is an early response of oxidative stress. $\mathrm{C} 2 \mathrm{C} 12$ myotubes were treated with $100 \mu \mathrm{M} t-\mathrm{BHP}$ or $20 \mu \mathrm{M} F C C P$ for the indicated time points, and then OPA1 levels and mitochondrial inner membrane proteases were analyzed. For $t$-BHP treatment, a western blot image of the L-OPA1 and S-OPA1 proteins (a) and associated statistical analysis (b). For FCCP treatment, a western blot image of the L-OPA1 and S-OPA1 proteins (c) and associated statistical analysis (d). (e) Afg3l2 mRNA level under both $t$-BHP and FCCP treatment. (f) A western blot image of AFG312 under $t$-BHP treatment, $(\mathbf{g}$ ) a western blot image of AFG312 under FCCP treatment and associated statistical analysis (h). Values are means \pm S.E.M. from at least three independent experiments. ${ }^{*} P<0.05,{ }^{* \star} P<0.01$

HT-AC prevents oxidative stress-induced OPA1 cleavage. As significant mitochondrial function loss was induced by $t$-BHP, whereas mitochondrial content was not affected, we thereby assumed that mitochondrial morphology change might be the major contributor of mitochondrial dysfunction. Further analysis showed that HT-AC pretreatment could sufficiently inhibit $t$-BHP-induced OPA1 cleavage (Figures $7 a$ and b). Although HT-AC was unable to prevent FCCPinduced MMP loss (Supplementary Figure S3), FCCPinduced ROS overproduction (Supplementary Figure S3) as well as OPA1 cleavage (Figures $7 c$ and d) were sufficiently inhibited by HT-AC. Meanwhile, $t$-BHP-induced Afg312 increase on mRNA and protein levels was prevented by HT$\mathrm{AC}$ (Figures 7e and f). As shown in Figure 7g, $t$-BHP induced significant mitochondrial structural and morphological changes, as evidenced by irregular cristae and swollen mitochondria, that were also efficiently inhibited by HT-AC pretreatment (Figure $7 \mathrm{~g}$ ).

HT-AC inhibits oxidative stress-induced MyHC abnormality. As both OPA1 cleavage and mitochondrial dysfunction were sufficiently inhibited by HT-AC pretreatment, we thereby investigated the changes of MyHC content. As expected, the decrease in $\mathrm{MyHC}$ protein induced by $t$-BHP (Figures $8 a$ and $c$ ) and FCCP (Figures $8 b$ and $d$ ) was both significantly inhibited by HT-AC. A similar pattern was observed for the mRNA levels of the MyHC isoforms MyHC I, MyHC IIB and MyHC IIx (Figure 8e). In addition, immunocytochemistry analysis indicated that irregular distribution of $\mathrm{MyHC}$, in addition to decreased protein content, and HT-AC pretreatment successfully maintained a normal distribution of MyHC in the C2C12 myotubes (Figure 8e). 
a

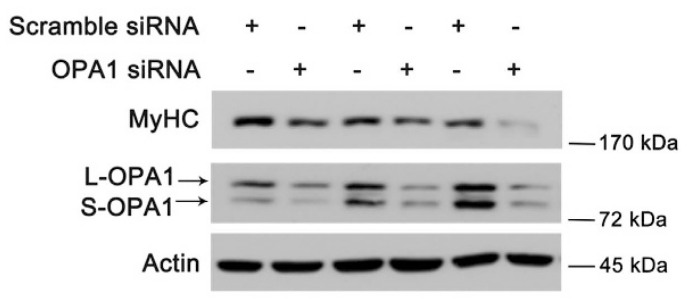

C

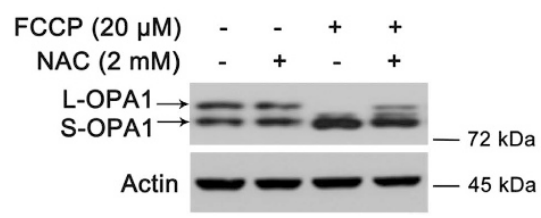

e

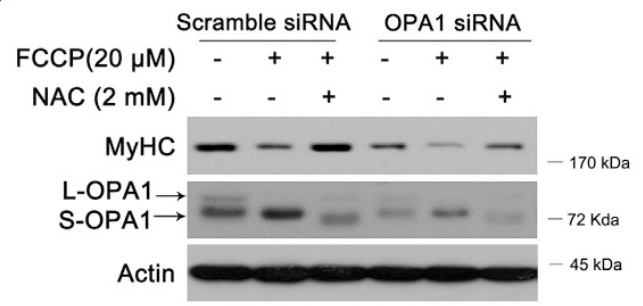

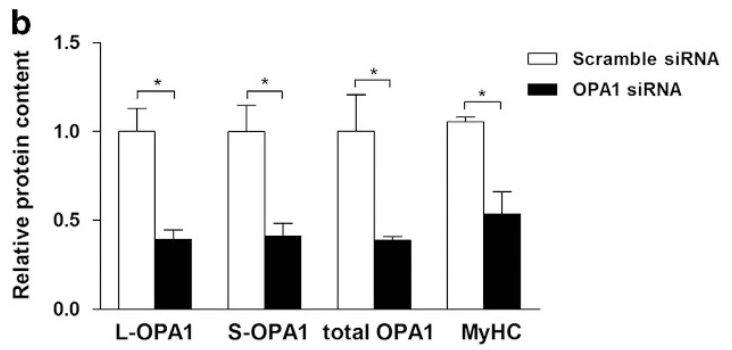

d

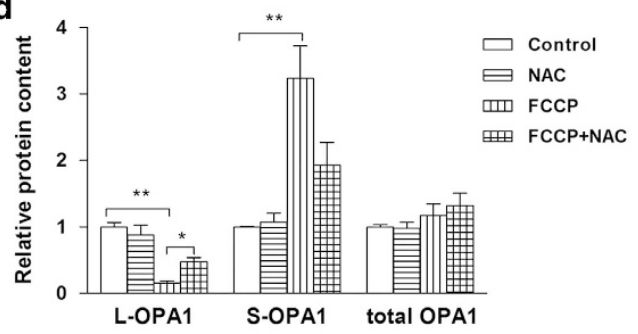

f

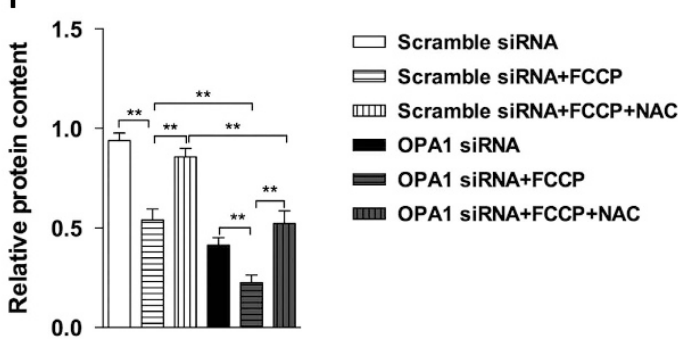

Figure 5 Oxidative stress decreases MyHC content through modulation of OPA1. C2C12 myotubes were transfected with OPA1 siRNA or with scrambled siRNA as negative control. After $72 \mathrm{~h}$ of transfection, OPA1 and MyHC protein contents were analyzed by western blotting ((a) western blot image; (b) statistical analysis). Following pretreatment with $2 \mathrm{mM} \mathrm{NAC}$ for $30 \mathrm{~min}, \mathrm{C} 2 \mathrm{C} 12$ myotubes were treated with $20 \mu \mathrm{M}$ FCCP for $2 \mathrm{~h}$ and OPA1 contents were analyzed ((c) western blot image; (d) statistical analysis). Myotubes were transfected with OPA1 siRNA for $72 \mathrm{~h}$ followed by $2 \mathrm{mM}$ NAC or/and $20 \mu \mathrm{M} \mathrm{FCCP}$ for another $2 \mathrm{~h}$, and OPA1 and MyHC protein contents were analyzed ((e) western blot image; (f) statistical analysis). Values are means \pm S.E.M. from at least three independent experiments. ${ }^{\star} P<0.05,{ }^{* \star} P<0.01$

\section{Discussion}

Muscle abnormalities can lead to devastating consequences, including insulin sensitivity decline, inflammatory reactions and a decrease in exercise capacity. Among the various physiological and pathological contributions, mitochondrial dysfunction is no doubt an important one because of its role in ATP and ROS production. Recent studies have indicated that impaired mitochondrial dynamics could affect muscle cell glucose uptake and contribute to insulin resistance, ${ }^{29}$ and mitochondrial dynamic remodeling was closely associated with strenuous exercise-induced muscle damage. As a known regulator of mitochondrial fusion, OPA1 could affect mitochondrial morphology and cellular function through modulation of its cleavage. ${ }^{15,30,31}$ Therefore, in the current study, we investigated the involvement of OPA1 cleavage in oxidative stress-induced mitochondrial dysfunction and muscle degeneration.

$t$-BHP was employed as a model of exogenous oxidative stress for its better stability than hydrogen peroxide. Despite a structural difference, both hydrogen peroxide and $t$-BHP have been widely used in muscle and other studies. ${ }^{6,32-34} \mathrm{C} 2 \mathrm{C} 12$ myotube differentiation was confirmed by time-dependent MyHC expression. After $t$-BHP treatment, rapid MMP, cell viability and ATP loss were observed, consistent with previous studies in pancreatic $\beta$-cells, ${ }^{35}$ human aortic smooth muscle cells (HASMCs) and human umbilical vein endothelial cells (HUVECs). ${ }^{36}$ It is interesting to note that $t$-BHP induced rapid ROS overproduction, but at $2 \mathrm{~h}$, instead of accumulating, the ROS level was generally decreased. We thereby assumed that long-term treatment with t-BHP impaired mitochondrial basal respiration and led to less ROS production, and this is supported by the data in Figure 6. Along with mitochondrial dysfunction, MyHC, as well as its isoforms $\mathrm{MyHC} \mathrm{I,} \mathrm{MyHC} \mathrm{Ilb}$ and $\mathrm{MyHC}$ lix, were found to be decreased significantly and accompanied by obvious myotube morphology changes. In muscle cells, myosin II generates sufficient force to complete the physiological activities through energy release from ATP hydrolysis. ${ }^{37} \mathrm{MyHC}$ functions as a subunit of myosin II, and its isoform expression levels were used as markers identifying muscle fiber type. ${ }^{38}$ Therefore, it is obvious that oxidative stress induced significant muscle cell degeneration in this study. Because $t$-BHP was an exogenous stress, we wondered whether endogenous stress would show similar effects. FCCP was then used to inhibit mitochondrial function and induce ROS overproduction in $15 \mathrm{~min}$. More efficiently, FCCP induced significant $\mathrm{MyHC}$ decrease in $2 \mathrm{~h}$ that was sufficiently inhibited by the free radical scavenger NAC. In addition, Li et al. ${ }^{39}$ reported that TNF-a could induce skeletal 


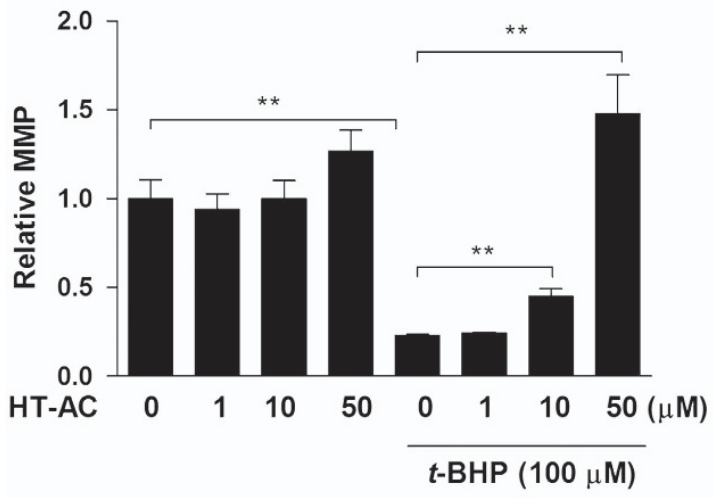

C
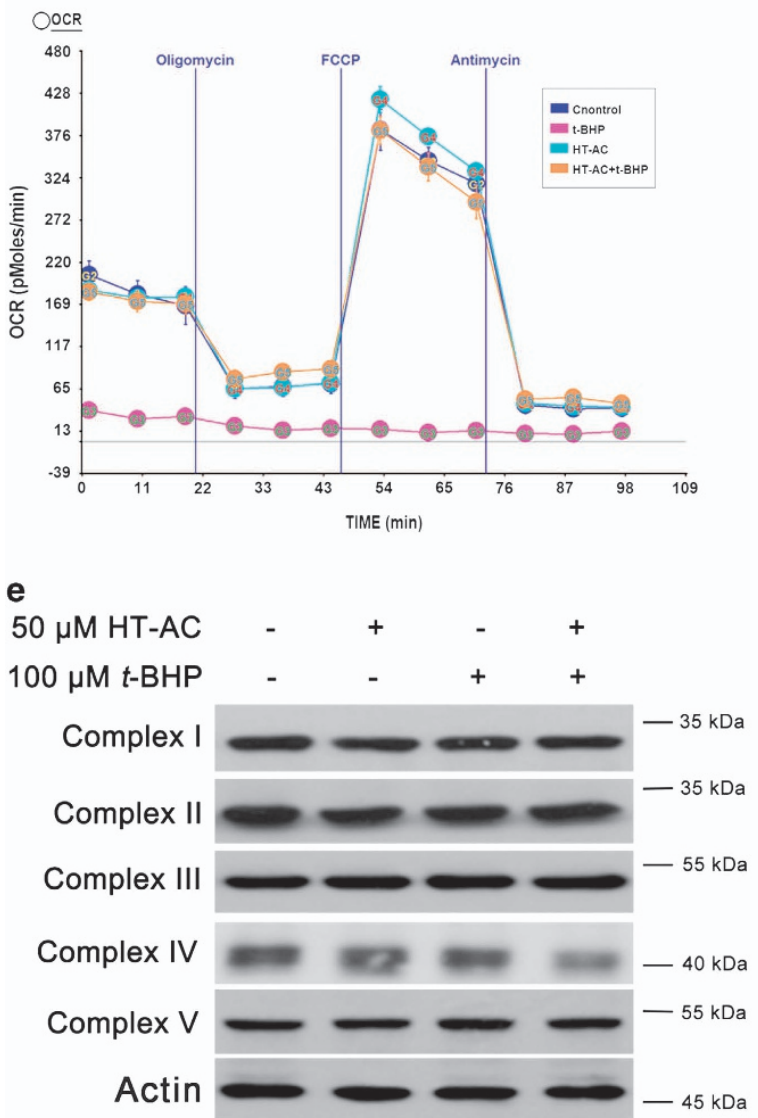

b

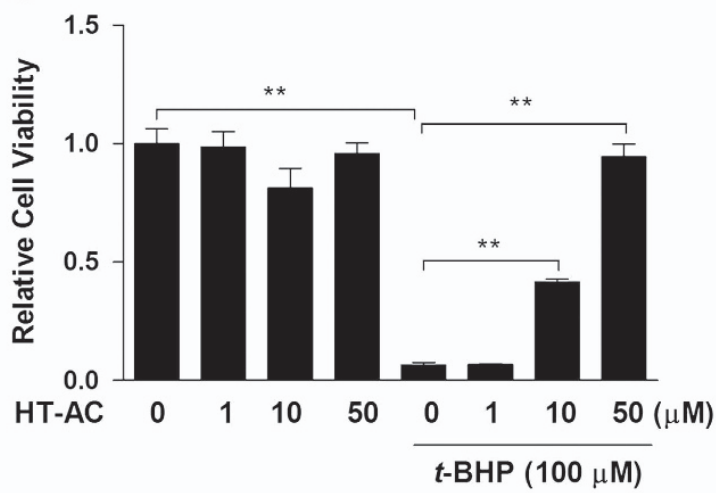

d

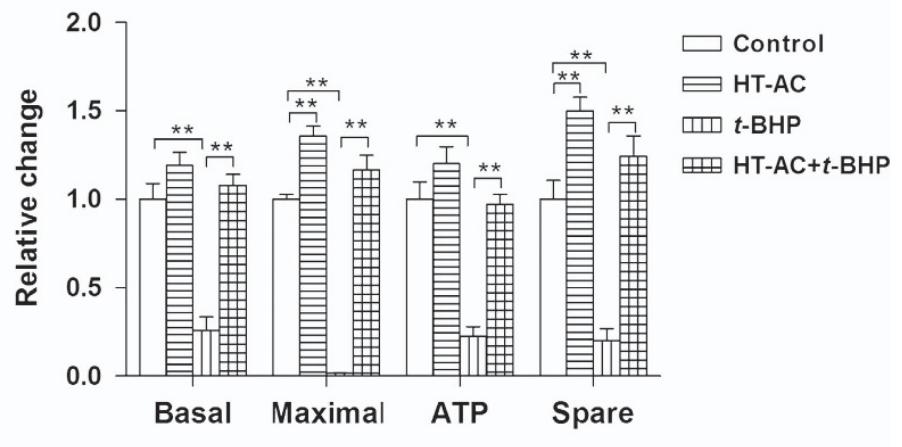

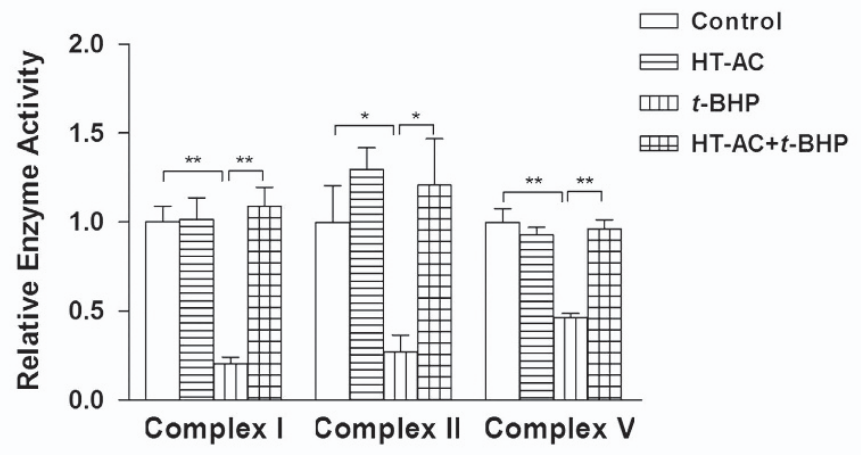

Figure 6 Effects of HT-AC on t-BHP-induced mitochondrial dysfunction. C2C12 myotubes were treated with HT-AC at doses of 1,10 and $50 \mu \mathrm{M}$ for $24 \mathrm{~h}$, followed by $100 \mu \mathrm{M}$ $t$-BHP for an additional $24 \mathrm{~h}$. The protective effects of HT-AC on mitochondrial membrane potential (a) and cell viability (b) were analyzed. C2C12 myotubes were treated with $50 \mu \mathrm{M} \mathrm{HT}$-AC for $24 \mathrm{~h}$ followed by $100 \mu \mathrm{M} \mathrm{t}$-BHP for an additional $24 \mathrm{~h}$. Basal, maximal and spare mitochondrial respiration capacity were analyzed as well as the ATP potential ((c) respiration curve; (d) statistical analysis). The mitochondrial complex subunits were analyzed (e), and complex I, II and V activities were evaluated with purified mitochondria (f). Values are means \pm S.E.M. from at least three independent experiments. ${ }^{\star} P<0.05,{ }^{\star \star} P<0.01$

muscle protein loss through modulation of ROS content. Collectively, our data suggested that ROS overproductionassociated oxidative stress was the major effector that induced $\mathrm{MyHC}$ decline and potential muscle degeneration. In addition to total MyHC protein loss, the immunocytochemistry data in Figure 8 show that irregular distribution of MyHC in myotubes and the underlying mechanism warrants further investigation.
OPA1 is known to be located in the mitochondrial inner membrane and to regulate mitochondrial fusion. Mutation of OPA1 led to neuronal degeneration with mitochondrial respiration abnormalities, swollen and vacuolated mitochondrial shape and loss of cristae organization in muscle fibers. ${ }^{40}$ in addition, patients with OPA1 mutation showed defective mitochondrial ATP production in skeletal muscle. ${ }^{41}$ In the muscle fibers of aging subjects, OPA1 levels were significantly 
a

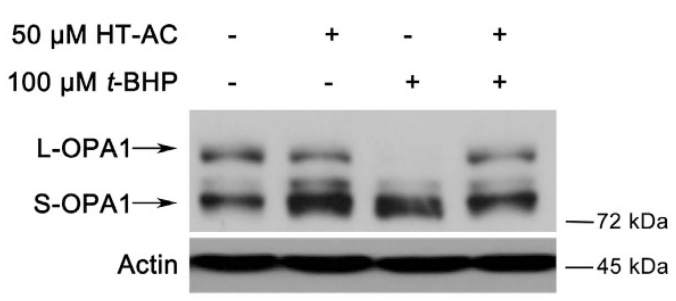

C

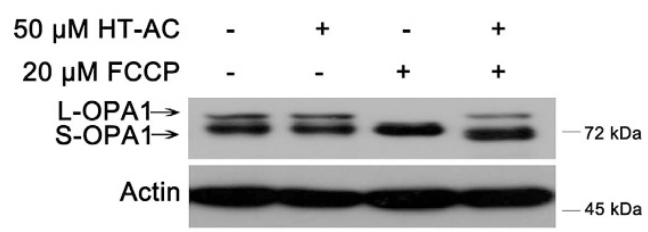

e

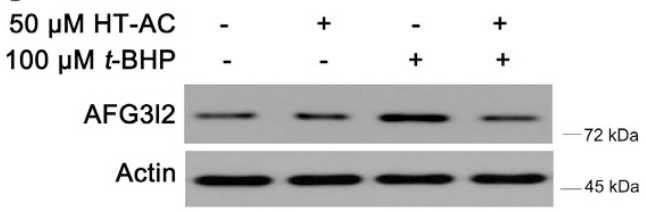

f

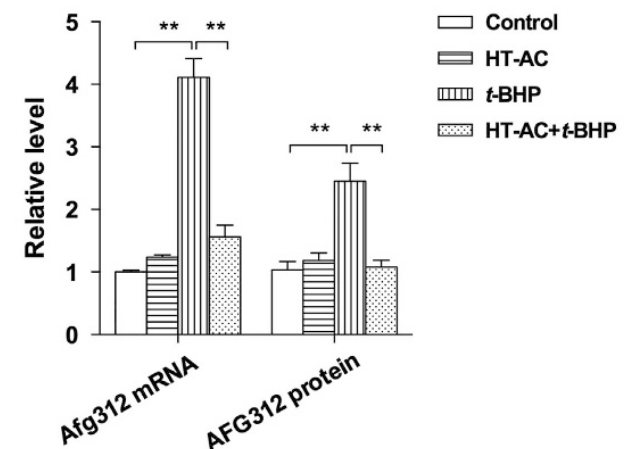

b

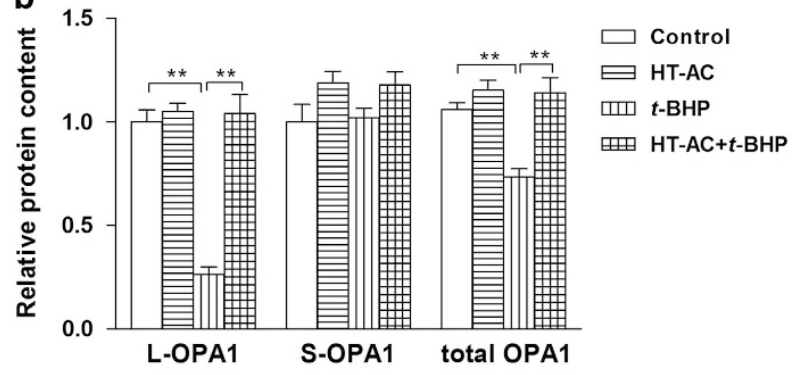

d

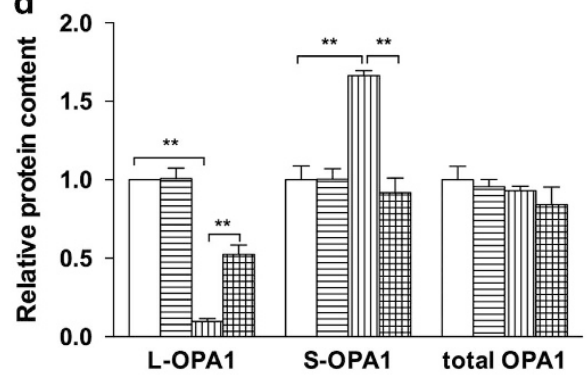

$\square$ Control

$\square$ HT-AC

mm FCCP

FCCP+HT-AC

\section{g}

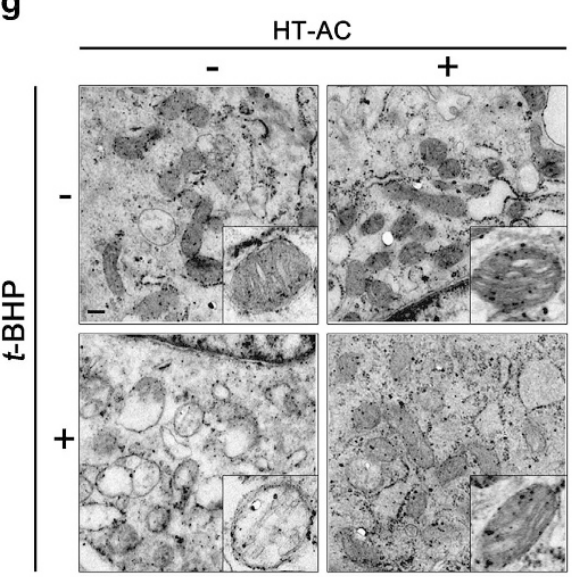

Figure $7 \mathrm{HT}$-AC inhibits oxidative stress-induced OPA1 cleavage. C2C12 myotubes were treated with $50 \mu \mathrm{M} \mathrm{HT}$-AC for $24 \mathrm{~h}$ followed by $100 \mu \mathrm{M}$ t-BHP for additional $24 \mathrm{~h}$ or $20 \mu \mathrm{M}$ FCCP for additional $2 \mathrm{~h}$. OPA1 protein levels were analyzed after t-BHP treatment ((a) western blot image; (b) statistical analysis) and FCCP treatment ((c) western blot image; (d) statistical analysis). Afg3l2 mRNA and protein levels were analyzed after $6 \mathrm{~h} t$-BHP treatment ((e) western blot image; (f) statistical analysis). Mitochondrial morphology was analyzed by transmission electron microscopy at the original magnification of $\times 10 \mathrm{k}$ or $\times 50 \mathrm{k}(\mathrm{g})$. Values are means \pm S.E.M. from at least three separate experiments. ${ }^{*} P<0.05,{ }^{* *} P<0.01$

decreased, whereas other mitochondrial dynamic regulators were not affected. ${ }^{42}$ In this study, we found that OPA1 underwent rapid cleavage in response to both $t$-BHP and FCCP challenge, and accumulated S-OPA1 was observed at $2 \mathrm{~h}$. It was indicated that abnormal OPA 1 cleavage contributed to cristae disorganization, ${ }^{43,44}$ and similar mitochondrial morphology was also observed after $t$-BHP treatment in this study. Regarding OPA1 cleavage, several proteases have been claimed to be responsible, and in this study, only Afg3l2 was found to be sensitive to oxidative stress and increased significantly after both $t$-BHP and FCCP treatment. Consistent with a NAC effect on MyHC content, the cleavage of OPA1 was also inhibited by NAC. Together with the data showing an OPA1 knockdown-induced MyHC decline, we speculated that
ROS might affect MyHC content through the modulation of OPA1. Thus, both NAC and OPA1 siRNAs were applied in $\mathrm{C} 2 \mathrm{C} 12$ myotubes, and the FCCP-induced MyHC decline was not inhibited by NAC under OPA1 knockdown. Our study provides evidence suggesting a close association between OPA1 cleavage and MyHC content. However, the detailed regulatory mechanisms were not explored, and this is indeed a limitation of this study. Further investigations should focus on understating how abnormal OPA1 cleavage contributes to MyHC decline.

Despite a limited understanding of mechanisms accounting for muscle disorders, effective nutritional intervention seems to be a better way to maintain health. As a major polyphenolic compound in olive oil, HT was found effective in metabolic 
a

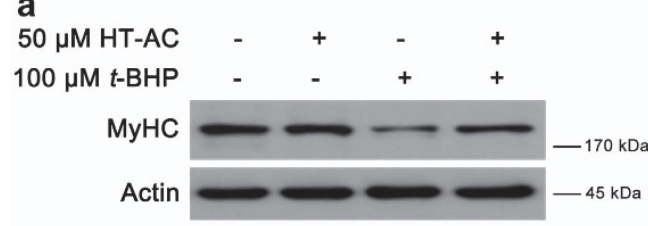

b
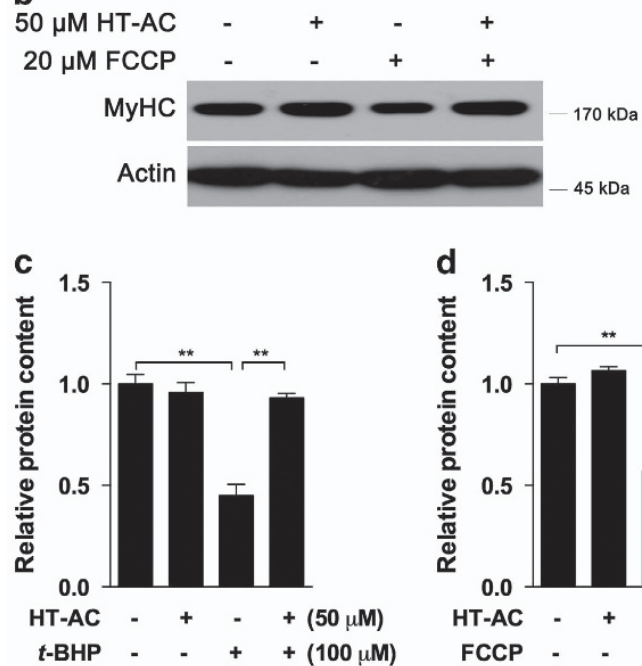

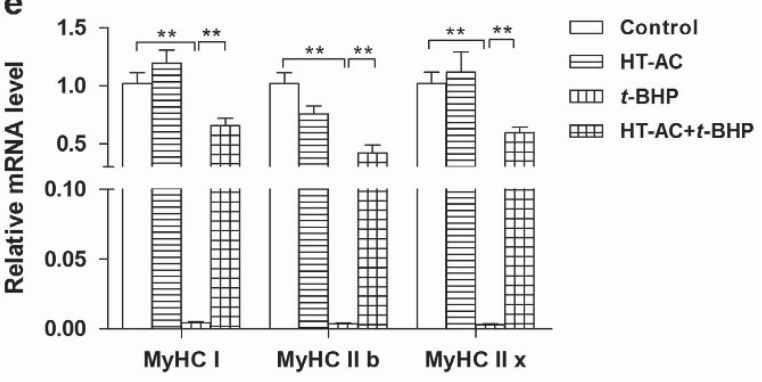

$\mathbf{f}$

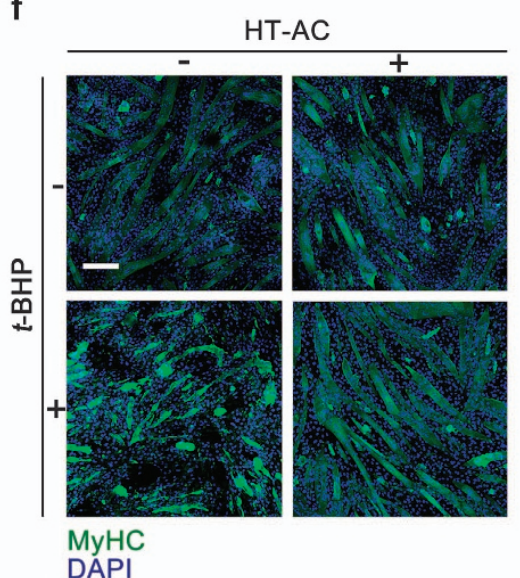

Figure 8 Effects of HT-AC on oxidative stress-induced MyHC abnormalities. C2C12 myotubes were treated with $50 \mu \mathrm{M} \mathrm{HT-AC}$ for $24 \mathrm{~h}$ followed by $100 \mu \mathrm{M} t$-BHP for additional $24 \mathrm{~h}$ or $20 \mu \mathrm{M} \mathrm{FCCP}$ for additional $2 \mathrm{~h}$. MyHC protein levels were determined after $t$-BHP treatment ((a) western blot image; (c) statistical analysis) and FCCP treatment ((b) western blot image; (d) statistical analysis). The mRNA levels of MyHC isoforms were analyzed by real-time PCR (e). MyHC distribution was observed by immunocytochemistry analysis (f). Values are means \pm S.E.M. from at least three separate experiments. ${ }^{*} P<0.05,{ }^{* \star} P<0.01$

syndrome, ${ }^{10}$ unloading-induced muscle atrophy ${ }^{45}$ and strenuous exercise-induced muscle damage. ${ }^{6}$ In this study, HT-AC, another effective compound that has recently been identified, was investigated. As expected, HT-AC significantly prevented $t$-BHP-induced OPA1 cleavage as well as the induction of Afg3l2. The significant morphology change in mitochondria induced by $t$-BHP was also normalized by HT-AC. Analysis of mitochondrial function revealed significant protection by HTAC on mitochondrial basal, maximal, spare respiration and complex activities. Because the mitochondrial complex subunits were not affected by either $t$-BHP or HT-AC, we concluded that the decreased mitochondrial function was potentially attributable to morphology changes. More importantly, the decrease in MyHC protein content and mRNA content, as well as the irregular distribution of MyHC in $\mathrm{C} 2 \mathrm{C} 12$ myotubes, were all sufficiently normalized by HT-AC, suggesting that HT-AC may be an efficient nutrient preventing mitochondrial dysfunction-associated muscle disorders.

Taken together, the results of the current study indicate that oxidative stress induced significant mitochondrial dysfunction and MyHC protein loss, potentially by modulating OPA1 cleavage. In addition, HT-AC works as an effective nutrient preventing OPA1 cleavage, mitochondrial dysfunction and muscle cell degeneration. Hopefully, potential new targets and effective nutrients provided by further study could contribute to the development of new strategy for the prevention and treatment of muscle disorders.

\section{Materials and Methods}

Chemicals. $t-B H P, F C C P$, antimycin A, oligomycin and ATP assay kit were from Sigma (St. Louis, MO, USA). Fetal bovine serum (FBS) was from PAA Laboratories GmbH (Linz, Austria). High glucose Dulbecco's modified Eagle's medium (DMEM), horse serum (HS), JC-1 (5,5,6,6-tetrachloro-1,1,3,3-tetraethylbenzimidazolylcarbocyanine iodide), DAPI and antibodies against complex I, II, III, IV and V were from Invitrogen (Carlsbad, CA, USA). HRP-conjugated anti-mouse/rabbit IgG antibodies were purchased from Jackson ImmunoResearch Laboratories (West Grove, PA, USA). The antibodies against MyHC, AFG312, PARP and cleaved PARP were from Santa Cruz Biotechnology (Santa Cruz, CA, USA). The antibodies against $\beta$-actin, cleaved caspase 3 and cleaved caspase 9 were from Cell Signaling Technology (Danvers, MA, USA). The antibody against OPA1 was from BD (Franklin Lakes, NJ, USA). OPA1 siRNA oligo and PCR primers for Afg3l2, MyHC I, MyHC llb, MyHC Ilx, Murf-1, Atrogin-1 and $\beta$-actin were synthesized by Genepharma (Shanghai, China).

Cell culture. Mouse $\mathrm{C} 2 \mathrm{C} 12$ myoblasts were purchased from the ATCC (Manassas, VA, USA) and cultured in DMEM supplemented with $100 \mathrm{U} / \mathrm{ml}$ penicillin and $100 \mu \mathrm{g} / \mathrm{ml}$ streptomycin and $10 \%$ FBS. Cell cultures were maintained at $37^{\circ} \mathrm{C}$ in a humidified atmosphere of $95 \%$ air and $5 \% \mathrm{CO}_{2}$. Medium was changed every 2 days. For the study of muscle cells, cells were differentiated as previous report. ${ }^{6}$

MTT assay for cell viability. $\mathrm{C} 2 \mathrm{C} 12$ myoblasts were cultured in 96-well plates. After differentiation and treatment, cell viability was determined by the addition of MTT (3-[4,5-dimethylthiazol-2-yl]-2,5-diphenyltetrazolium bromide). Optical densities were read at $555 \mathrm{~nm}$ using a microplate spectrophotometer (Multiskan Ascent, Thermo Fisher Scientific Inc., Waltham, MA, USA).

JC-1 assay for MMP. C2C12 myoblast were cultured in 96-well plates. After differentiation and treatment, MMP was detected with JC-1. For quantitative fluorescence measurement, cells were incubated with $\mathrm{JC}-1$ staining and scanned using a microplate fluorometer (Fluoroskan Ascent, Thermo Fisher Scientific Inc.) at $488 \mathrm{~nm}$ excitation and 535 and $590 \mathrm{~nm}$ emission wavelengths to measure green 
and red JC-1 fluorescence, respectively. The red/green fluorescence intensity ratio reflects MMP.

Intracellular ATP levels. C2C12 myoblasts were cultured in six-well plates. After differentiation and treatment, cells were lysed with $0.5 \%$ Triton X-100 in $100 \mathrm{mM}$ glycine buffer, $\mathrm{pH}$ 7.4. Intracellular ATP level assays were performed using an ATP assay kit following the manufacturer's protocol. ATP was consumed and light was emitted when firefly luciferase catalyzed the oxidation of D-luciferin. ${ }^{46}$

ROS measurement. C2C12 myoblasts were cultured in six-well plates. After differentiation and treatment, the generation of intracellular ROS was determined using the fluorescence of $2^{\prime}, 7^{\prime}$-dichlorofluorescein (H2DCF-DA). H2DCF-DA was incubated with live cells in serum-free medium for $45 \mathrm{~min}$, and then cells were collected with PBS. After centrifugation at $1000 \mathrm{~g}$ for $5 \mathrm{~min}$ at $4^{\circ} \mathrm{C}$, cells were suspended with cold PBS. Cells were analyzed by flow cytometry (BD Biosciences, Franklin Lakes, NJ, USA).

Cell oxygen consumption rate (OCR) measurement. $\mathrm{C} 2 \mathrm{C} 12$ myoblasts were seeded in XF 24-well microplates (Seahorse Bioscience, Billerica, MA, USA). After differentiation and treatment, oxygen consumption was measured with extracellular flux analysis (Seahorse Biosciences). The final concentrations of mitochondrial inhibitors were at $10 \mu \mathrm{M}$ antimycin $\mathrm{A}, 6 \mu \mathrm{M}$ FCCP and $10 \mu \mathrm{M}$ oligomycin. Basal respiration is the baseline oxygen consumption reading before compounds are injected. Maximal respiration represents the maximum OCR measurement value after FCCP injection. Spare respiratory capacity is calculated by noting the OCR response to FCCP, and dividing that number by the basal respiration to get a percentage. After detection, cells numbers were calculated and OCR was adjusted accordingly.

Transmission electron microscope (TEM) assays. C2C12 myoblasts were cultured in six-well plates. After differentiation and treatment, cells were washed with PBS and then collected for centrifugation at $1000 \mathrm{~g}$ for $10 \mathrm{~min}$ at $4{ }^{\circ} \mathrm{C}$. The supernatant was discarded, and cells were fixed with $2.5 \%$ glutaraldehyde in $0.1 \mathrm{M}$ phosphate buffer and the TEM assay was performed following a previous study.

Myotube mitochondrial isolation. C2C12 myoblast were seeded in 10-cm dishes. After differentiation and treatment, cells were washed with cold PBS and collected for centrifugation at $1000 \mathrm{~g}$ for $10 \mathrm{~min}$ at $4^{\circ} \mathrm{C}$. The supernatant was discarded and the pellet was resuspended in a hypotonic RSB buffer $(10 \mathrm{mM} \mathrm{NaCl}$, $2.5 \mathrm{mM} \mathrm{MgCl}_{2}, 10 \mathrm{mM}$ Tris base, $\mathrm{pH} 7.5$ ) and allowed to swell. The swollen cells were homogenized with a Dounce homogenizer. MS buffer $(210 \mathrm{mM}$ mannitol, $70 \mathrm{mM}$ sucrose, $5 \mathrm{mM}$ Tris base, $1 \mathrm{mM}$ EDTA, pH 7.5) was added and then the mixture was centrifuged at $1000 \mathrm{~g}$ for $10 \mathrm{~min}$ at $4^{\circ} \mathrm{C}$. The pellet was then centrifuged at $17000 \mathrm{~g}$ for $15 \mathrm{~min}$ at $4^{\circ} \mathrm{C}$ to obtain the mitochondrial pellet. The pellet was resuspended with isolation buffer (Tris base $100 \mathrm{mM}$, sucrose $100 \mathrm{mM}$, EDTA $10 \mathrm{mM}, \mathrm{KCl} 46 \mathrm{mM}, \mathrm{BSA}, 0.5 \%$ (W/W), $\mathrm{pH} 7.5)$ and stored at $-80^{\circ} \mathrm{C}$ for further analysis.

Mitochondrial complex activity assays. NADH-ubiquinone reductase (complex I), succinate-CoQ oxido-reductase (complex II), CoQ-cytochrome $c$ reductase (complex III), cytochrome $c$ oxidase (complex IV) and ATP synthase (complex V) activities were measured spectrophotometrically using conventional assays following a previous report. ${ }^{46,47}$ All of the activities were adjusted by the expression level of each complex.

MyHC immunocytochemistry analysis. C2C12 myoblasts were cultured on cover glass discs in six-well plates. After differentiation and treatment, cells were washed with PBS and then fixed with 4\% paraformaldehyde in PBS for 20 min at room temperature. After being rinsed with PBS, the cells were permeabilized with $0.25 \%$ Triton X-100 for 10 min at room temperature and then blocked with $1 \%$ BSA in PBST for $1 \mathrm{~h}$ at room temperature and washed with PBS. Cells were then incubated with antibody against $\mathrm{MyHC}(1: 500)$ in $1 \% \mathrm{BSA}$ overnight at $4^{\circ} \mathrm{C}$ and further incubated with FITC-labeled Goat Anti-Rabbit IgG (Beyotime, Jiangsu, China) in $1 \%$ BSA for $1 \mathrm{~h}$ at room temperature in the dark. After washing with PBS, the cells were incubated with $0.5 \mu \mathrm{g} / \mathrm{ml}$ DAPI for $5 \mathrm{~min}$ and visualized by confocal microscopy (Zeiss, Jena, Germany).
Western blot analysis. Samples were lysed with western and IP lysis buffer (Beyotime). The lysates were homogenized and centrifuged at $13000 \mathrm{~g}$ for $10 \mathrm{~min}$ at $4{ }^{\circ} \mathrm{C}$. The supernatants were collected and the protein concentrations were determined using the BCA Protein Assay kit. Equal amounts $(10 \mu \mathrm{g})$ of each protein sample were applied to SDS-PAGE gels, transferred to pure nitrocellulose membranes (PerkinEImer Life Sciences, Boston, MA, USA) and blocked with 5\% nonfat milk. The membranes were incubated with the first antibody at $4^{\circ} \mathrm{C}$ overnight. Then, the membranes were incubated with anti-rabbit or anti-mouse secondary antibodies at room temperature for $1 \mathrm{~h}$. Chemiluminescent detection was performed using an ECL western blotting detection kit (Thermo Fisher, Rockford, IL, USA). The results were analyzed by Quantity One software (Bio-Rad, Shanghai, China) to obtain the optical density ratio of target proteins relative to $\beta$-actin.

SiRNA transfection. Transfection with siRNA targeting OPA1 was performed using the target sequence from mouse OPA1, and scrambled siRNA was used as negative control. After differentiation in six-well plates, myotubes were prepared for transfection. The transfection was performed using Lipofectamine 2000 (Invitrogen), as described in the supplier's manual. SiRNA $(200 \mathrm{pmol})$ was incubated per well containing serum-free DMEM for $24 \mathrm{~h}$. The medium was replaced with DMEM containing $2 \% \mathrm{HS}$ for another $48 \mathrm{~h}$, and then the cells were treated with different conditions.

Real-time PCR. Total RNA was extracted from the cells using TRlzol reagent (Roche, Basel, Switzerland) following the manufacturer's protocol. Reverse transcription was performed using the PrimeScript RT-PCR Kit (Otsu, Shiga, Japan) followed by semi-quantitative real-time PCR using specific primers. The primer sequences were as follows: Afg312, 5'-AAAACTCCGGTTGATGGGCA-3' (forward) and 5'-CCGGTTCTCCCCTTCTATGC-3' (reverse); MyHC I, 5'-CCAG GGGCAAACAGGCATTCACT-3' (forward) and 5'-CTTCCACTGGGCCACTTCACT GTT-3' (reverse); Mrf4, 5'-GCAGAGGGCTCTCCTTTGTA-3' (forward) and 5'-GGT AGCTGCTTTCCGACGAT-3' (reverse); Myod, 5'-CCAGGACACGACTGCTTTCT-3' (forward) and 5'-TCTGGTGAGTCGAAACACGG-3' (reverse); Myogenin, 5'-GA GACATGAGTGCCCTGACC-3' (forward) and 5'-AGGCTTTGGAACCGGATAGC-3' (reverse); MyHC Ilb, 5'-GTGATTTCTCCTGTCACCTCTC-3' (forward) and 5'-G GAGGACCGCAAGAACGTGCTGA-3' (reverse); MyHC $\| x, 5^{\prime}$-TGAAGGGCG GCAAGAAGCAGAT-3' (forward) and 5'-GCGGAATTTGGCCAGGTTGACA-3' (reverse); $\beta$-actin $5^{\prime}$-ACGGCCAGGTCATCACTATTG-3' (forward) and $5^{\prime}$-CA CAGGATTCCATACCCAAGAAG-3' (reverse).

Statistical analysis. The results are presented as the mean \pm S.E.M. Statistical analyses were conducted using one-way ANOVA followed by least significant difference post hoc analysis or an unpaired $t$-test. For all analyses, values of $P<0.05$ were considered statistically significant.

\section{Conflict of Interest}

The authors declare no conflict of interest.

Acknowledgements. We are supported by the National Natural Science Foundation of China (81201023, 31370844), Tianjin Science and Technology Planning Major Project (12JCZDJC34400), Tianjin Education committee Sci-Tech Development Major Project (20112D05), Tianjin Key Labs and Tech-Platform Project (10SYSYJC28400), National 'Twelfth Five-Year' Plan for Science \& Technology Support (2012BAH30F03).

1. Timmons JA, Norrbom J, Scheele C, Thonberg H, Wahlestedt C, Tesch P. Expression profiling following local muscle inactivity in humans provides new perspective on diabetesrelated genes. Genomics 2006; 87: 165-172.

2. Kang C, Ji LL. Muscle immobilization and remobilization downregulates PGC-1alpha signaling and the mitochondrial biogenesis pathway. J Appl Physiol (1985) 2013; 115: 1618-1625.

3. Mecocci P, Fano G, Fulle S, MacGarvey U, Shinobu L, Polidori MC et al. Age-dependent increases in oxidative damage to DNA, lipids, and proteins in human skeletal muscle. Free Radic Biol Med 1999; 26: 303-308.

4. Dewys WD, Begg C, Lavin PT, Band PR, Bennett JM, Bertino JR et al. Prognostic effect of weight loss prior to chemotherapy in cancer patients. Eastern Cooperative Oncology Group. Am J Med 1980; 69: 491-497. 
5. O'Gorman P, McMillan DC, McArdle CS. Longitudinal study of weight, appetite, performance status, and inflammation in advanced gastrointestinal cancer. Nutr Cancer 1999; 35 127-129.

6. Feng Z, Bai L, Yan J, Li Y, Shen W, Wang Y et al. Mitochondrial dynamic remodeling in strenuous exercise-induced muscle and mitochondrial dysfunction: regulatory effects of hydroxytyrosol. Free Radic Biol Med 2011; 50: 1437-1446.

7. Casanova E, Baselga-Escudero L, Ribas-Latre A, Arola-Arnal A, Blade C, Arola L et al. Epigallocatechin gallate counteracts oxidative stress in docosahexaenoic acid-treated myocytes. Biochim Biophys Acta 2014; 1837: 783-791.

8. Kim B, Kim JS, Yoon Y, Santiago MC, Brown MD, Park JY. Inhibition of Drp1-dependent mitochondrial division impairs myogenic differentiation. Am J Physiol Regul Integr Comp Physiol 2013; 305: R927-R938.

9. Romanello V, Guadagnin E, Gomes L, Roder I, Sandri C, Petersen Y et al. Mitochondrial fission and remodelling contributes to muscle atrophy. EMBO J 2010; 29: 1774-1785.

10. Cao K, Xu J, Zou X, Li Y, Chen C, Zheng A et al. Hydroxytyrosol prevents diet-induced metabolic syndrome and attenuates mitochondrial abnormalities in obese mice. Free Radic Biol Med 2014; 67: 396-407.

11. Olichon A, Emorine LJ, Descoins E, Pelloquin L, Brichese L, Gas N et al. The human dynamin-related protein OPA1 is anchored to the mitochondrial inner membrane facing the inter-membrane space. FEBS Lett 2002; 523: 171-176.

12. Suen DF, Norris KL, Youle RJ. Mitochondrial dynamics and apoptosis. Genes Dev 2008; 22 1577-1590.

13. Delettre C, Griffoin JM, Kaplan J, Dollfus H, Lorenz B, Faivre L et al. Mutation spectrum and splicing variants in the OPA1 gene. Hum Genet 2001; 109: 584-591.

14. Merkwirth C, Dargazanli S, Tatsuta T, Geimer S, Lower B, Wunderlich FT et al. Prohibitins control cell proliferation and apoptosis by regulating OPA1-dependent cristae morphogenesis in mitochondria. Genes Dev 2008; 22: 476-488.

15. Ishihara N, Fujita Y, Oka T, Mihara K. Regulation of mitochondrial morphology through proteolytic cleavage of OPA1. EMBO J 2006; 25: 2966-2977.

16. Baricault L, Segui B, Guegand L, Olichon A, Valette A, Larminat F et al. OPA1 cleavage depends on decreased mitochondrial ATP level and bivalent metals. Exp Cell Res 2007; 313: 3800-3808.

17. Griparic L, Kanazawa $T$, van der Bliek AM. Regulation of the mitochondrial dynamin-like protein Opa1 by proteolytic cleavage. J Cell Biol 2007; 178: 757-764.

18. Macvicar TD, Lane JD. Impaired OMA1 dependent OPA1 cleavage and reduced DRP1 fission activity combine to prevent mitophagy in OXPHOS dependent cells. J Cell Sci 2014; 127(Pt 10): 2313-2325

19. Kieper N, Holmstrom KM, Ciceri D, Fiesel FC, Wolburg H, Ziviani E et al. Modulation of mitochondrial function and morphology by interaction of Omi/HtrA2 with the mitochondrial fusion factor OPA1. Exp Cell Res 2010; 316: 1213-1224.

20. Maltecca F, Aghaie A, Schroeder DG, Cassina L, Taylor BA, Phillips SJ et al. The mitochondrial protease AFG3L2 is essential for axonal development. J Neurosci 2008; 28: 2827-2836

21. Maltecca F, Magnoni R, Cerri F, Cox GA, Quattrini A, Casari G. Haploinsufficiency of AFG3L2, the gene responsible for spinocerebellar ataxia type 28 , causes mitochondriamediated Purkinje cell dark degeneration. J Neurosci 2009; 29: 9244-9254.

22. Dorn GW 2nd, Clark CF, Eschenbacher WH, Kang MY, Engelhard JT, Warner SJ et al. MARF and Opa1 control mitochondrial and cardiac function in Drosophila. Circ Res 2011; 108: $12-17$.

23. Parra V, Verdejo HE, Iglewski M, Del Campo A, Troncoso R, Jones D et al. Insulin stimulates mitochondrial fusion and function in cardiomyocytes via the Akt-mTOR-NFkappaB-Opa-1 signaling pathway. Diabetes 2014; 63: 75-88.

24. Pelucchi C, Bosetti C, Negri E, Lipworth L, La Vecchia C. Olive oil and cancer risk: an update of epidemiological findings through 2010. Curr Pharm Des 2011; 17: 805-812.

25. Perez-Martinez P, Garcia-Rios A, Delgado-Lista J, Perez-Jimenez F, Lopez-Miranda J. Mediterranean diet rich in olive oil and obesity, metabolic syndrome and diabetes mellitus. Curr Pharm Des 2011; 17: 769-777.

26. Fito M, Cladellas M, de la Torre $\mathrm{R}$, Marti J, Alcantara M, Pujadas-Bastardes $M$ et al. Antioxidant effect of virgin olive oil in patients with stable coronary heart disease: a randomized, crossover, controlled, clinical trial. Atherosclerosis 2005; 181: 149-158.

27. Pierno S, Tricarico D, Liantonio A, Mele A, Digennaro C, Rolland JF et al. An olive oil-derived antioxidant mixture ameliorates the age-related decline of skeletal muscle function. Age (Dordr) 2014; 36: 73-88.

28. Lisete-Torres $\mathrm{P}$, Losada-Barreiro S, Albuquerque $\mathrm{H}$, Sanchez-Paz V, Paiva-Martins $\mathrm{F}$, Bravo-Diaz C. Distribution of hydroxytyrosol and hydroxytyrosol acetate in olive oil emulsions and their antioxidant efficiency. J Agric Food Chem 2012; 60: 7318-7325.

29. del Campo A, Parra V, Vasquez-Trincado C, Gutierrez T, Morales PE, Lopez-Crisosto C et al. Mitochondrial fragmentation impairs insulin-dependent glucose uptake by modulating Akt activity through mitochondrial Ca2+ uptake. Am J Physiol Endocrinol Metabol 2014; 306 E1-E13.

30. Spinazzi M, Cazzola S, Bortolozzi M, Baracca A, Loro E, Casarin A et al. A novel deletion in the GTPase domain of OPA1 causes defects in mitochondrial morphology and distribution, but not in function. Hum Mol Genet 2008; 17: 3291-3302.

31. Duvezin-Caubet S, Jagasia R, Wagener J, Hofmann S, Trifunovic A, Hansson A et al. Proteolytic processing of OPA1 links mitochondrial dysfunction to alterations in mitochondrial morphology. J Biol Chem 2006; 281: 37972-37979.

32. Zhang Q, Seltmann H, Zouboulis CC, Konger RL. Involvement of PPARgamma in oxidative stress-mediated prostaglandin $\mathrm{E}(2)$ production in SZ95 human sebaceous gland cells. J Invest Dermatol 2006; 126: 42-48.

33. Marchetti M, Resnick L, Gamliel E, Kesaraju S, Weissbach H, Binninger D. Sulindac enhances the killing of cancer cells exposed to oxidative stress. PLOS One 2009; 4: e5804.

34. Krishnan N, Dickman MB, Becker DF. Proline modulates the intracellular redox environment and protects mammalian cells against oxidative stress. Free Radic Biol Med 2008; 44: 671-681.

35. Maechler $\mathrm{P}$, Jornot $\mathrm{L}$, Wollheim $\mathrm{CB}$. Hydrogen peroxide alters mitochondrial activation and insulin secretion in pancreatic beta cells. J Biol Chem 1999; 274: 27905-27913.

36. Ballinger SW, Patterson C, Yan CN, Doan R, Burow DL, Young CG et al. Hydrogen peroxideand peroxynitrite-induced mitochondrial DNA damage and dysfunction in vascular endothelial and smooth muscle cells. Circ Res 2000; 86: 960-966.

37. Tyska MJ, Warshaw DM. The myosin power stroke. Cell Motil Cytoskeleton 2002; 51: $1-15$.

38. Pandorf CE, Caiozzo VJ, Haddad F, Baldwin KM. A rationale for SDS-PAGE of MHC isoforms as a gold standard for determining contractile phenotype. J Appl Physiol (1985) 2010; 108: 222-222. author reply 226.

39. Li YP, Schwartz RJ, Waddell ID, Holloway BR, Reid MB. Skeletal muscle myocytes undergo protein loss and reactive oxygen-mediated NF-kappaB activation in response to tumor necrosis factor alpha. FASEB J 1998; 12: 871-880.

40. Sarzi E, Angebault C, Seveno M, Gueguen N, Chaix B, Bielicki G et al. The human OPA1delTTAG mutation induces premature age-related systemic neurodegeneration in mouse. Brain 2012; 135(Pt 12): 3599-3613.

41. Lodi R, Tonon C, Valentino ML, Manners D, Testa C, Malucelli E et al. Defective mitochondrial adenosine triphosphate production in skeletal muscle from patients with dominant optic atrophy due to OPA1 mutations. Arch Neurol 2011; 68: 67-73.

42. Joseph AM, Adhihetty PJ, Buford TW, Wohlgemuth SE, Lees HA, Nguyen LM et al. The impact of aging on mitochondrial function and biogenesis pathways in skeletal muscle of sedentary high- and low-functioning elderly individuals. Aging Cell 2012; 11: 801-809.

43. Frezza C, Cipolat S, Martins de Brito O, Micaroni M, Beznoussenko GV, Rudka T et al. OPA1 controls apoptotic cristae remodeling independently from mitochondrial fusion. Cell 2006; 126: 177-189.

44. Cipolat S, Rudka T, Hartmann D, Costa V, Serneels L, Craessaerts K et al. Mitochondrial rhomboid PARL regulates cytochrome $\mathrm{c}$ release during apoptosis via OPA1-dependent cristae remodeling. Cell 2006; 126: 163-175

45. Liu J, Peng Y, Feng Z, Shi W, Qu L, Li Y et al. Reloading functionally ameliorates disuseinduced muscle atrophy by reversing mitochondrial dysfunction, and similar benefits are gained by administering a combination of mitochondrial nutrients. Free Radic Biol Med 2014; 69: $116-128$

46. Li X, Liu Z, Luo C, Jia H, Sun L, Hou B et al. Lipoamide protects retinal pigment epithelial cells from oxidative stress and mitochondrial dysfunction. Free Radic Biol Med 2008; 44: 1465-1474.

47. Sun L, Luo $\mathrm{C}$, Long J, Wei $\mathrm{D}$, Liu J. Acrolein is a mitochondrial toxin: effects on respiratory function and enzyme activities in isolated rat liver mitochondria. Mitochondrion 2006; 6 : 136-142.

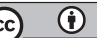

Cell Death and Disease is an open-access journal published by Nature Publishing Group. This work is licensed under a Creative Commons Attribution 4.0 International Licence. The images or other third party material in this article are included in the article's Creative Commons licence, unless indicated otherwise in the credit line; if the material is not included under the Creative Commons licence, users will need to obtain permission from the licence holder to reproduce the material. To view a copy of this licence, visit http://creativecommons.org/licenses/by/4.0 